\title{
Analysis of TJ Economic Vulnerability Based on Set Pair Analysis
}

\author{
Lixia Zhang \\ Management School, Tianjin Normal University, Tianjin, China \\ Email: tjsdzlx@163.com
}

How to cite this paper: Zhang, L.X. (2019) Analysis of TJ Economic Vulnerability Based on Set Pair Analysis. Journal of Service Science and Management, 12, 116-125. https://doi.org/10.4236/jssm.2019.122007

Received: January 13, 2019

Accepted: January 29, 2019

Published: February 1, 2019

Copyright $\odot 2019$ by author(s) and Scientific Research Publishing Inc. This work is licensed under the Creative Commons Attribution International License (CC BY 4.0).

http://creativecommons.org/licenses/by/4.0/

\begin{abstract}
The vulnerability evaluation index system of Tianjin urban economic system was established; entropy method was used to determine the weight of each evaluation index. Then, the vulnerability of Tianjin urban economic system was measured from the perspectives of economy sensitivity and resilience using set pair analysis method. Studies show that during 2000-2014, the sensitivity of the Tianjin urban economic system to cope with adverse disturbance, showing upward fluctuation, while the resilience showed a trend of rising. Generally, the vulnerability of Tianjin urban economic system is rising frequently and slowly.
\end{abstract}

\section{Keywords}

Vulnerability, Sensitivity, Resilience, Set Pair Analysis, Tianjin

\section{Introduction}

Timmerman P. first proposed the concept of vulnerability in 1981. Vulnerability refers to the ability of system or system components to bear and restore risk events, and it is used in the field of natural science [1]. Briguglio L. is the first person to apply the concept of vulnerability to the field of economy, and establish the economic vulnerability index [2]. In 1999, UNDP formally puts forward the concept of "economic vulnerability", defining the economic vulnerability as "the capacity of enduring the damage due to suffer from unexpected events in the process of economic development" [3]. Since then, a large number of research findings on economic vulnerability have emerged.

Summary on these articles about economic vulnerability mainly focuses on the tourism economic vulnerability [4], coalmine economic vulnerability [5], petroleum economic vulnerability [6], regional economic vulnerability [7], and 
financial economic vulnerability [8], however, the study of a particular city economic vulnerability is relatively few.

Tianjin is located in the center of the Bohai coastal region in China, and only $120 \mathrm{~km}$ away from the capital city. The area of Tianjin is 11.9 thousand square kilometers, and the resident population is 10.1 million. Tianjin is the largest port city in North China as well as one of the earliest eastern coastal port cities in China. Early, Tianjin is the national business development center, even is at the core position in the economic development of Asia. After the liberation of China, Tianjin gradually fades out of the stage of economic development. In the past 10 years, the central government puts forward "the collaborative development of Beijing Tianjin Hebei", "Bohai coastal region economic circle" and other major strategies, which make the economic development of Tianjin meet a new opportunity. This paper takes Tianjin economy as the example, on the basic of economic vulnerability theory, using entropy method to analyze the economic vulnerability, sensitivity and resilience from 2000 to 2014, and further discusses the factors that cause Tianjin economic vulnerability increase slowly.

\section{The Construction of Index System and the Determination of Weight}

\subsection{The Construction of Index System}

Urban economic vulnerability is a comprehensive attribute of a variety of economic indicators of a city, including two aspects of sensitivity and resilience. Sensitivity refers to the ability to withstand destruction when the economic system suffers the internal disorder and external shocks, the weaker the sensitivity is, and the less vulnerable the economic system is. Resilience refers to the ability to quickly adjust the economic system from crisis to security and stability, the stronger the resilience is, the stronger the self maintenance ability of the economic system is, and it can recover quickly from the adverse influence. The interaction of economic sensitivity and resilience jointly determine the economic vulnerability. When the economic vulnerability is large, the ability of the economy to withstand all kinds of crisis destruction is worse, and the speed of economy returns to steady state is slower, the whole economic system is in a unsafe state, whereas the economic system is more secure.

Economy sensitivity and resilience are multiple structural variables, which contain very complex economic environmental factors. In order to comprehensively reflect the degree of Tianjin economic vulnerability, this paper combines with the actual situation of Tianjin's social economy, finance and energy development, and with reference to the vulnerability index selection method from Yang Aiting and Wujian [9], to establish the vulnerability evaluation index system of Tianjin urban economic system, the specific contents are as shown in Table 1 .

The column 4 of Table 1 shows the meaning of each index from positive and negative aspects: if sensitivity index is $(+)$, it means that the greater index value 
Table 1. The vulnerability evaluation index system of Tianjin urban economic system.

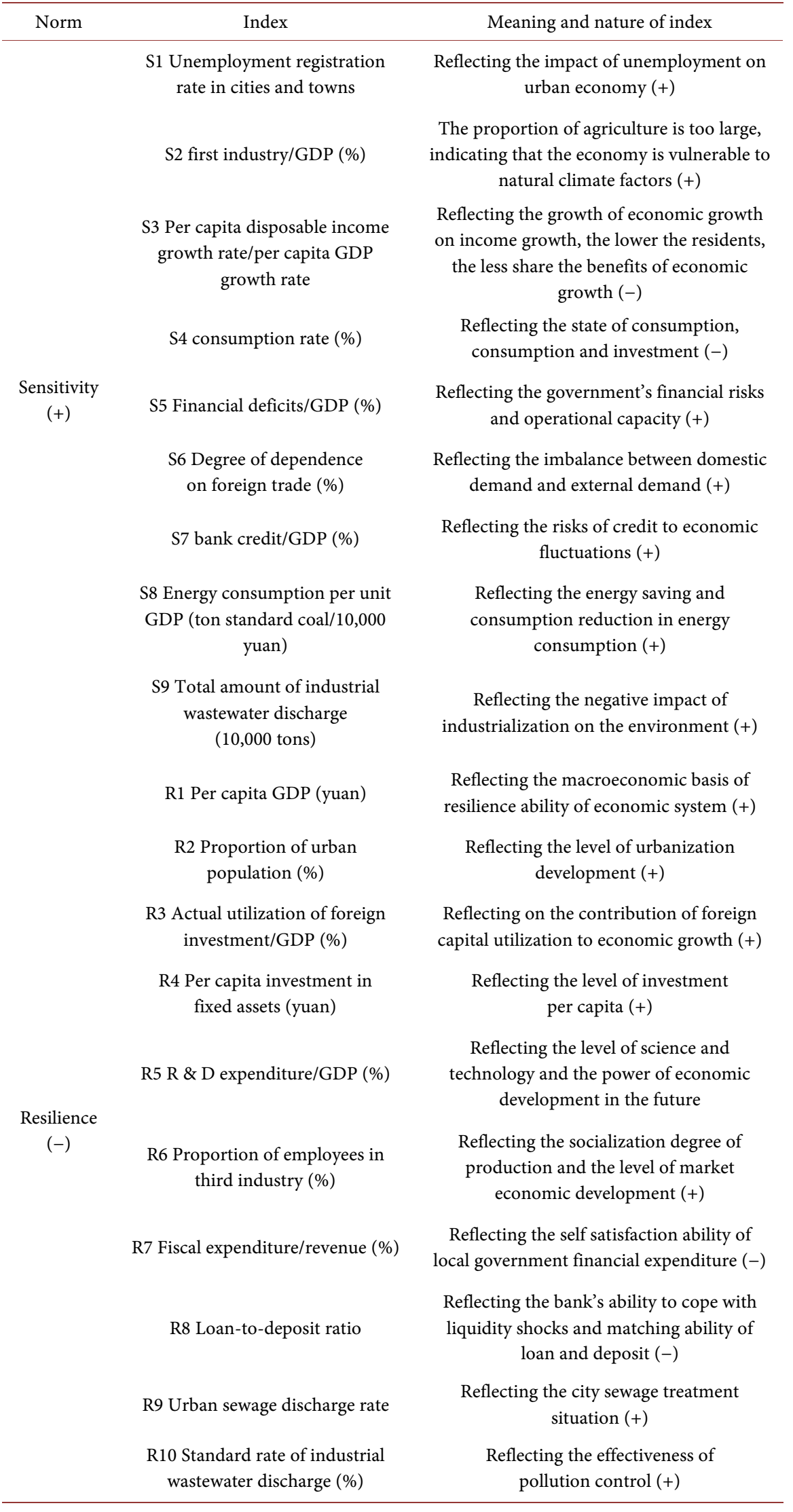


is, the greater the economy sensitivity is, the weaker the ability of the economic system to withstand destruction is; if sensitivity index is (-), it means that the smaller index value is, the smaller the economy sensitivity is, the stronger the ability of the economic system to withstand destruction is. As for resilience, if resilience index is $(+)$, it means that the greater index value is, the stronger the economy resilience is, the stronger coping ability of the economy is, and so on.

All the original data in Table 1 come from the Tianjin Statistical Yearbook and Tianjin statistical yearbook on science and technology. In order to ensure the integrity of data, this paper chooses data from 2000 to 2014.

\subsection{The Determination of Index Weight}

Due to the different influence on economic vulnerability, it is necessary to assign weight to each evaluation index, in order to reflect the true extent of the economic vulnerability. This paper uses entropy method to determine the weight of each evaluation index in order to make the weight calculation objective. The main calculation steps are as follows [10]:

Step 1: standardization of data

Because the quantities and dimensions of each index are different, it is necessary to standardize the data. When the index is greater and more favorable to evaluate the high level target, the positive index calculation method is adopted. The formula is (1).

$$
X_{i p}^{\prime}=\frac{X_{i p}-\min \left\{X_{p}\right\}}{\max \left\{X_{p}\right\}-\min \left\{X_{P}\right\}}
$$

When the index is smaller and more favorable to evaluate the high level target, the negative index calculation method is adopted.

$$
X_{i p}^{\prime}=\frac{\max \left\{X_{p}\right\}-X_{i p}}{\max \left\{X_{p}\right\}-\min \left\{X_{P}\right\}}
$$

Step 2: calculate the proportion of index value of item $p$ in the $i$ year. The expression is (3):

$$
Y_{i p}=\frac{X_{i p}^{\prime}}{\sum_{i=1}^{m} X_{i p}^{\prime}}
$$

Step 3: calculate the information entropy of item $p$. The expression is (4):

$$
e_{p}=-(\ln m)^{-1} \sum_{i=1}^{m}\left(Y_{i p} \times \ln Y_{i p}\right),\left(0 \leq e_{p} \leq 1\right)
$$

Step 4: calculate the weight of item p. The expression is (4):

$$
w_{p}=\frac{\left(1-e_{p}\right)}{\sum_{p=1}^{n}\left(1-e_{p}\right)}
$$

In the formula, $X_{i p}$ denotes the evaluation index value of item $p$ in the $i$ year; $\max \left\{X_{p}\right\}$ and $\min \left\{X_{p}\right\}$ are the maximum and minimum values of the evaluation index in all years, $\mathrm{m}$ is the number of evaluation years, and $n$ is the number of 
index.

According to the above entropy method, the economy sensitivity and resilience index are brought into the formula to calculate. The weight value of Tianjin economic vulnerability evaluation index is obtained in Table 2 .

\section{Construction of Theoretical Model}

Economic system is a complex system with multi variable interaction, and the economic development has typical uncertainty characteristics, so this paper introduce set pair analysis method (SPA) to analyze economic vulnerability evaluation, in order to estimate the development trend of Tianjin economic vulnerability in 2000-2014. The core idea of SPA is to analyze the certain and uncertain factors in set pairs, connecting set $E$ and set $U$ as a set $H$, Under specific circumstance $Q$, according to a set of characteristics, separating the certainty into the "same" and "opposites", calling the uncertainty as "difference", in order to establish a connection formula to analyze the object and system from same, opposite and different aspects. Therefore, the set pair analysis is mainly to analyze the characteristics of the set $H$, so as to get the property $N$, among which has $S$ is set $E$ and set $U$ in common, $P$ is opposite, $F=N-S-P S$ is uncertain. The connection degree of two sets $\mu$ is [11]:

$$
\mu=\frac{S}{N}+\frac{F}{N} i+\frac{P}{N} j=a+b i+c j
$$

In the formula (6), $a, b, c$ respectively refer to same degree, difference degree and opposite degree of set $E$ and set $U$ under circumstance $Q . i$ and $j$ are the marks and coefficients of difference degree and opposite degree. The value of $J$ is -1 , and the value range of $i$ is $[-1,1] . a, b, c$ characterize the connection of two sets from different aspects. By comparing them, the connection degree of the set can be preliminarily analyzed.

According to the specific analysis, the corresponding evaluation index in Tianjin economic system are determined as set $E$, the evaluation criteria are determined as set $U, U$ and $E$ are combined as set $H\{E, U\}$, set $U$ and set $E$ exist a certain and uncertain relationship among "same", "different" or "opposite". Therefore, the vulnerability evaluation of Tianjin urban economic system can be seen as the process of comparative analysis between set $U$ and set $E$.

Specifically, the vulnerability of Tianjin urban economic system is $Q=\{E, G, W, D\}$, and the evaluation scheme $E=\left\{e_{1}, e_{2}, \cdots, E_{m}\right\}$, each evaluation scheme has $n$ index $G=\left\{g_{1}, g_{2}, \cdots, g_{n}\right\}$, the index weight $=\left\{\omega_{1}, \omega_{2}, \cdots, \omega_{n}\right\}$,

Table 2. Weight value of each evaluation index.

\begin{tabular}{ccccccccccc}
\hline Sensitivity index & S1 & S2 & S3 & S4 & S5 & S6 & S7 & S8 & S9 & \\
\hline Weights & 0.026 & 0.141 & 0.279 & 0.063 & 0.073 & 0.129 & 0.097 & 0.106 & 0.083 & \\
Resilience index & R1 & R2 & R3 & R4 & R5 & R6 & R7 & R8 & R9 & R10 \\
Weights & 0.151 & 0.081 & 0.075 & 0.194 & 0.065 & 0.085 & 0.135 & 0.069 & 0.104 & 0.041 \\
\hline
\end{tabular}


the evaluation index value is marked as $d_{k p}(k=1,2, \cdots, m ; p=1,2, \cdots, n)$, the evaluation matrix of $Q$ is:

$$
D=\left|\begin{array}{cccc}
d_{11} & d_{12} & \cdots & d_{1 n} \\
d_{21} & d_{22} & \cdots & d_{2 n} \\
\vdots & \vdots & \ddots & \vdots \\
d_{m 1} & d_{m 2} & \cdots & d_{m n}
\end{array}\right|
$$

We compare the worst evaluation index and the best evaluation index in each scheme in the same space, in order to form the optimal scheme set $U=\left\{u_{1}, u_{2}, \cdots, u_{n}\right\}$ and worst scheme set $V=\left\{v_{1}, v_{2}, \cdots, v_{n}\right\}$, according to set $\left\{v_{p}, u_{p}\right\}$, the same degree and opposite degree $c_{k p}$ of $d_{k p}$ in evaluation matrix $D$ are as follows:

When $d_{k p}$ has a positive effect on the evaluation results:

$$
\left\{\begin{array}{l}
a_{k p}=\frac{d_{k p}}{u_{p}+v_{p}} \\
c_{k p}=\frac{u_{p} v_{p}}{d_{k p}\left(u_{p}+v_{p}\right)}
\end{array}\right.
$$

When $d_{k p}$ has a negative effect on the evaluation results:

$$
\left\{\begin{array}{l}
a_{k p}=\frac{u_{p} v_{p}}{d_{k p}\left(u_{p}+v_{p}\right)} \\
c_{k p}=\frac{d_{k p}}{u_{p}+v_{p}}
\end{array}\right.
$$

The connection degree $\mu$ of set pair $\left\{E_{k}, U\right\}$ in $[U, V]$ is:

$$
\left\{\begin{array}{l}
\mu_{(E, U)}=a_{k}+b_{k} i+c_{k} j \\
a_{k}=\sum w_{p} a_{k p} \\
c_{k}=\sum w_{p} c_{k p}
\end{array}\right.
$$

The closeness degree $r_{k}$ of scheme $E_{k}$ and the optimal scheme is:

$$
r_{k}=\frac{a_{k}}{a_{k}+c_{k}}
$$

$r_{k}$ index reflects the association between the scheme $E_{k}$ and the optimal scheme set, and the larger $r_{k}$ is, the closer the evaluated object is to the evaluation criteria. The vulnerability degree of Tianjin urban economic system can be analyzed according to $r_{k}$ The greater the index is, the more fragile Tianjin urban economic system is, contrarily, the more robust Tianjin urban economic system is.

\section{Evaluation of Tianjin Economic Vulnerability}

According to theory of set pair analysis method, we introduce the value of vulnerability index of Tianjin urban economic system from 2000 to 2014 to the corresponding formula, and the results are shown in Table 3. 
Table 3. The vulnerability, sensitivity and resilience of Tianjin urban economic system.

\begin{tabular}{cccccccccc}
\hline \multirow{2}{*}{ Years } & \multicolumn{3}{c}{ Sensitivity index } & \multicolumn{3}{c}{ Resilience index } & \multicolumn{3}{c}{ Vulnerability index } \\
\cline { 2 - 9 } & $\mathrm{a}$ & $\mathrm{c}$ & $\mathrm{r}$ & $\mathrm{a}$ & $\mathrm{c}$ & $\mathrm{r}$ & $\mathrm{a}$ & $\mathrm{c}$ & $\mathrm{r}$ \\
\hline 2000 & 0.456 & 0.635 & 0.418 & 0.361 & 0.583 & 0.382 & 0.558 & 0.635 & 0.468 \\
2001 & 0.486 & 0.571 & 0.459 & 0.374 & 0.543 & 0.408 & 0.559 & 0.593 & 0.485 \\
2002 & 0.505 & 0.544 & 0.481 & 0.376 & 0.523 & 0.419 & 0.565 & 0.571 & 0.497 \\
2003 & 0.655 & 0.464 & 0.585 & 0.360 & 0.513 & 0.412 & 0.664 & 0.502 & 0.512 \\
2004 & 0.561 & 0.475 & 0.541 & 0.402 & 0.455 & 0.469 & 0.566 & 0.505 & 0.528 \\
2005 & 0.475 & 0.632 & 0.429 & 0.422 & 0.427 & 0.497 & 0.514 & 0.534 & 0.490 \\
2006 & 0.573 & 0.455 & 0.557 & 0.447 & 0.408 & 0.523 & 0.538 & 0.473 & 0.532 \\
2007 & 0.563 & 0.456 & 0.552 & 0.483 & 0.388 & 0.554 & 0.512 & 0.467 & 0.523 \\
2008 & 0.549 & 0.477 & 0.535 & 0.547 & 0.352 & 0.608 & 0.474 & 0.453 & 0.512 \\
2009 & 0.719 & 0.364 & 0.664 & 0.577 & 0.329 & 0.637 & 0.534 & 0.379 & 0.585 \\
2010 & 0.711 & 0.354 & 0.667 & 0.608 & 0.321 & 0.655 & 0.519 & 0.377 & 0.579 \\
2011 & 0.689 & 0.368 & 0.651 & 0.667 & 0.330 & 0.675 & 0.490 & 0.389 & 0.558 \\
2012 & 0.6078 & 0.452 & 0.573 & 0.711 & 0.315 & 0.693 & 0.444 & 0.407 & 0.521 \\
2013 & 0.608 & 0.438 & 0.581 & 0.749 & 0.309 & 0.708 & 0.434 & 0.404 & 0.518 \\
2014 & 0.649 & 0.403 & 0.617 & 0.793 & 0.304 & 0.723 & 0.442 & 0.386 & 0.534 \\
\hline
\end{tabular}

According to Table 3, we further draw the trend lines of vulnerability, sensitivity and resilience of Tianjin urban economic system from 2000 to 2014 in Figure 1.

Seen from the above Table 3 and Figure 1, the value of vulnerability of Tianjin economic system is fluctuant and slightly rising, which indicates that the robustness of vulnerability of Tianjin economic system is fluctuant, but in general, it is still in the right direction. As for sensitivity, the value increased from 0.418 in 2000 to 0.585 in 2003, and then fluctuated, by 2010 the vulnerability index reached a maximum value of 0.667 , indicating that there are many unstable factors disturbing Tianjin economic development. Fortunately, the resilience index showed a rising trend, dealing with the value increased from 0.382 in 2000 to 0.723 in 2014, which means that with the Tianjin economic development, the ability of the economic system to adjust its internal structure and respond to external shocks continues to improve. As for the trend of vulnerability of economic system, Tianjin urban economic system shows a sustained fluctuant rising trend, and there is a continuous small peak to 2009-2010, which reflects the vulnerability of Tianjin economic system during this period. The following is in-depth analysis from three aspects of sensitivity, resilience and vulnerability of Tianjin economic system.

The sensitivity of Tianjin economic system shows a large fluctuation trend, there are two big peaks: one is the economic sensitivity index from 0.585 in 2003 to 0.528 in 2004; the other is the sensitivity index from 0.535 in 2008 to 0.637 in 2010. As we all know, the two periods are special in the process of economic development, SARS nationwide broke out in 2003, although SARS can't affect the 


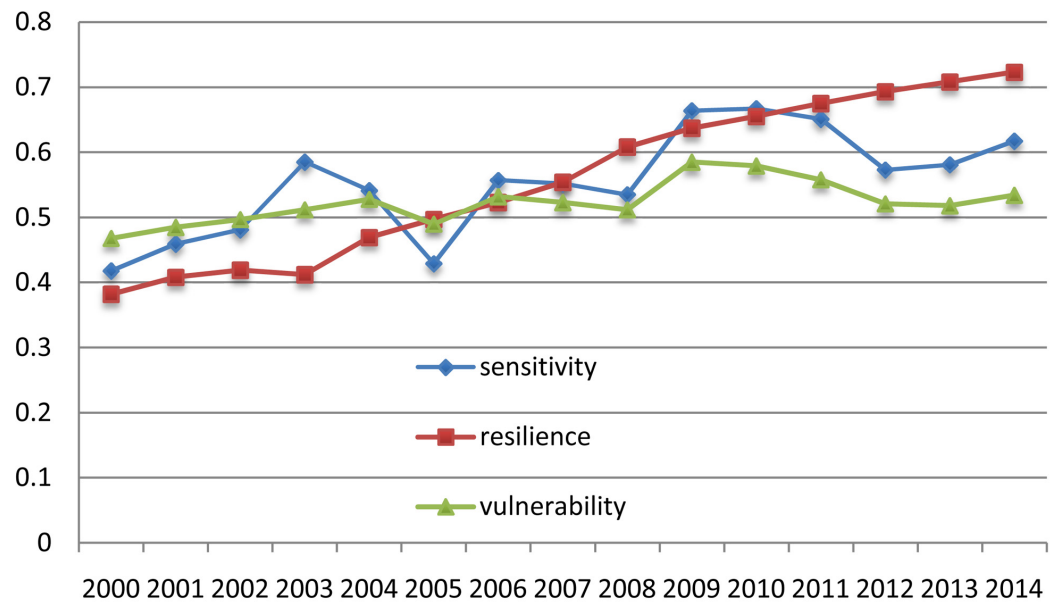

Figure 1. The trend lines of vulnerability, sensitivity and resilience of Tianjin urban economic system.

manufacturing industry, the service of tourism, transportation, catering and other industries was affected, which causes that the consumption in Tianjin greatly reduced; in addition, SARS also caused some impact on Tianjin import and export trade. 2008 is a more special period that the international financial crisis broke out, leading to rapid decline of export trade in Tianjin, the import and export of foreign trade turned into deficit, and the main export market demand also decreased significantly, the exports of state-owned and private enterprises are deeply affected; after the outbreak of the financial crisis, Tianjin foreign direct investment profits decreased rapidly, profit transfer increased, which has a wide influence on real economy, industrial development and technological progress in Tianjin. The outbreak and spread of the financial crisis had heavy influence of industry in Tianjin, especially ferrous metal smelting and rolling processing industry, electricity, heat production and supply industry, petroleum processing, coking and nuclear fuel processing, plastic products industry, pharmaceutical manufacturing industry, the port service industry, etc. All these caused the economic sensitivity index to show a growth trend, financial crisis effect makes the economic sensitivity index high for a period of time, the economic sensitivity index increased from 0.535 in 2008 to 0.637 in 2010, then decreased slightly from 2011 (0.651).

To deal with the resilience of Tianjin economic system, the value steadily increased from 0.468 in 2000 to 0.723 in 2014, a slight decline only in 2003 (the value decreased from 0.419 in 2002 to 0.412 in 2003). The geographical location advantage of Tianjin is obvious, the GDP has been in a growing trend, and the macroeconomic strength has been steadily increasing. In 2005, Tianjin Binhai New Area has been incorporated into the national development strategy in 11th Five-Year; in 2006, the State Council meeting defined Tianjin as "the center of Bohai Economic Rim"; In 2009, our country approved Tianjin Binhai New Area administrative division adjustment, Tianjin has formed a unique city form of "Shuangcheng Shuanggang". A series of policy support to Tianjin is the funda- 
mental reason for the constant growth of Tianjin economic resilience. In addition, from the perspective of the internal structure of the economy, the industrial structure of Tianjin economic development continues to be optimized, the proportion of the third industry to GDP is rising, and for the first time in 2015, it surpassed the second industry, accounting for 50\%; The investment structure has been continuously optimized, the financial industry has been developing steadily, the ability of independent innovation has been enhanced, the environmental protection has been strengthened, and the ecological environment has been further improved. All these factors make Tianjin urban economic resilience ability to increase; the economic resilience index value continues to rise.

As far as the vulnerability of Tianjin economic system, the vulnerability index showed a modest rise before 2008, and a significant increase from 2008 to 2011. The vulnerability index before 2008 was rising. It is related to the internal structure of the economic system, although the overall level of Tianjin economic development is constantly improving, there are many problems in Tianjin economic development, for example, the unreasonable industrial structure, $\mathrm{Al}$ though the proportion of the third industry development in GDP is increasing, it is still lagging behind; As for the internal industrial structure, manufacturing industry structure is not balanced, the proportion of heavy industry is too large; The level of industrial chain is not reasonable, and it is in the low level of vertical division of labor system. These factors have become constraining factors for the steady of the economy development, leading to a slight rise of vulnerability index before 2008. The economic vulnerability increased significantly from 2008 to 2011, the author thinks that the fundamental reason for the large fluctuation of economic vulnerability in Tianjin during this period is not the direct result of the uncoordinated and unstable internal system structure, but the external disturbance. That's the global financial crisis as the economic sensitivity analysis above.

Through the comparison among sensitivity, resilience and vulnerability of Tianjin economic system during 2000-2014, we can find that Tianjin economic system reflected relatively strong sensitivity in the presence of external disturbance, sensitivity index curve fluctuates greatly, however, due to the internal structure of Tianjin economic system is relatively coordinated, which cause the economy relatively stable, the economic resilience is not enhanced to rising trend, because of this, Although the sensitivity fluctuation range is obvious, the response plays a key role in solving the economic contradictions and reducing the economic vulnerability. It should be said that in the construction of market economy, Tianjin economic resilience is constantly increasing, which makes the economic system has a strong ability to restore itself.

\section{Acknowledgements}

The work described in this paper was fully supported by a grant from Tianjin higher school humanities and social science project (NO: 2017SK153). 


\section{Conflicts of Interest}

The author declares no conflicts of interest regarding the publication of this paper.

\section{References}

[1] Timmerman, P. (1981) Vulnerability, Resilience and the Collapse of Society: A Review of Models and Possible Climatic Applications. Institute for Environmental Studies, University of Toronto, Toronto, Canada.

[2] Briguglio, L. (1992) Preliminary Study on the Construction of an Index for Ranking Countries According to Their Economic Vulnerability. UNCTAD/LDC/Misc. 4.

[3] Guillaumont, P. (1999) On the Economic Vulnerability of Low-Income Countries. Report Prepared for the United Nations.

[4] Yang, Y. and Pan, H. (2015) Economic Vulnerability of Tourism Economy Dependent Economy and Its Evaluation Research. Inquiry into Economic Issues, 8, 161-169.

[5] Su, F., Zhang, P.Y. and Li, H. (2008) Evaluation on the Vulnerability of China's Coal Mining Cities. Geographical Research, 27, 907-916.

[6] Yang, Y.R., Wang, S.J. and Chen, X.H. (2015) Dynamic Evolution and Control Approaches of Petroleum City's Economic System Vulnerability: A Case Study of Daqing City. Geographical Research, 34, 456-463.

[7] Feng, Z.H., Liu, Y.X. and Yang, Y.L. (2010) The Cumulative Vulnerability Assessment of the Development of Beijing-Tianjin-Hebei Economic Circle. Modern Finance and Economics-Journal, 10, 63-68.

[8] Wu, Z.J. (2003) Financial Vulnerability: Theory and Empirical Analysis Based on China (1991-2000). Economic Review, No. 2, 96-128.

[9] Yang, A.T. and Wu, J. (2012) China's Economic System Vulnerability and Sustainable Development Involve: 15 Years of Sample. Reform, 216, 25-33.

[10] Chen, M.X., Lu, D.D. and Zhang, H. (2009) The Comprehensive Measure of China's Urbanization Level and Its Dynamic Factor Analysis. Acta Geographica Sinica, 4, 387-398.

[11] Zhao, K.Q. (2000) Set Pair Analysis and Its Preliminary Application. Zhejiang Science and Technology Press, Hangzhou. 